\title{
Stepwise Removal of the Fused Midline Parietal Bone to Avoid Superior Sagittal Sinus Injury in Infants with Sagittal Synostosis
}

\author{
Tufan HICDONMEZ1', Gaye TAYLAN FILINTE², Mehmet TIRYAKI ${ }^{1}$, Yusuf Emrah GERGIN¹ \\ ${ }^{1}$ Dr. Lutfi Kirdar Education and Research Hospital, Department of Neurosurgery, Istanbul, Turkey \\ ${ }^{2}$ Dr. Lutfi Kirdar Education and Research Hospital, Department of Plastic and Reconstructive Surgery, Istanbul, Turkey
}

\section{ABSTRACT}

This work describes a simple technique for the safe removal of the midline parietal bone with the synostotic sagittal suture in infants with sagittal synostosis to avoid dural tearing and bleeding from the superior sagittal sinus. The technique consists of stepwise removal of the midline parietal bone in three pieces instead of one piece, starting with the anterior one-third midline bone being safely freed from the underlying dural sinus and then transversely cut using a craniotome. The step is repeated twice for the middle and distal one-third of the bone respectively. Once the midline bone is bilaterally cut along its entire length, the stepwise elevation of the superior sagittal sinus dura using an elevator and removal of the midline bone in three pieces allows a safer, controlled procedure minimizing the risk of tearing the underlying dural sinus and preventing sinus bleeding in infants with sagittal synostosis.

KEYWORDS: Synostosis, Craniosynostosis, Scaphocephaly, Superior sagittal sinus

\section{INTRODUCTION}

$S^{m a r}$ agittal synostosis, scaphocephaly, is the one of the most common forms of craniosynostoses $(4,6,10)$. Many surgical techniques and modifications have been described for the correction of sagittal synostosis. The vertex craniectomies with the common feature of the removal of the fused midline bone with the fused sagittal suture are one of the major craniosynostosis surgeries for scaphocephaly $(1,2,4,5,9)$. However, surgical procedures for craniosynostosis in children carry a potentially high risk of complications because of significant blood loss $(5,11)$. Therefore, a number of methods have been described to reduce the risk of bleeding $(6,10,11)$.

We, herein, present our simple technique for step-wise removal of the fused midline parietal bone to avoid injury to the dura mater overlying the superior sagittal sinus of infants.

\section{SURGICAL TECHNIQUE}

Between February 2012 and July 2015, 23 children with sagittal synostosis underwent surgery at the Department of Neurosurgery. A total number of 20 consecutive infant cases with a mean age of 6.2 months (ranged between 3 and 12 months) were included in the study. All patients were placed either prone with extension of the head or in a supine position with anterior flexion of the head. A bicoronal skin incision was made. The general feature of all surgeries was a craniotomy of about a $4 \mathrm{~cm}$-wide strip along the sagittal suture to remove the midline parietal bone with a synostotic sagittal suture. Additional barrel-steve cuts were made bilaterally, with coronal and lambdoid sutures bilaterally left intact. The proposed technique is simple and it consists of a three-piece stepwise removal of the midline sagittal bone, each about 3 to $4 \mathrm{~cm}$ wide. The removal started at the level of the anterior fontanel. After a suturectomy performed at both sides of the anterior 
fontanel, an elevator was used to separate the dura and, thus, the superior sagittal sinus from the bone. Using a high-speed craniotome, the anterior edge of the parietal bone was cut. Then, bilateral parietal paramedian bone cuts were performed until the posterior fontanel. The stepwise removal of the midline sagittal bone in three pieces was then undertaken. At this point, starting at the anterior one-third of the midline bone, the bone was safely freed from the underlying dural sinus (Figure 1) and then transversely cut with the craniotome (Figure 2). The step was repeated twice for the middle and distal one-third of the bone respectively (Figures 3 and 4).

In all cases, the midline fused parietal bone was safely removed. No surgical complications in terms of superior sagittal sinus injury, dural tear, or peroperative bleeding were encountered.

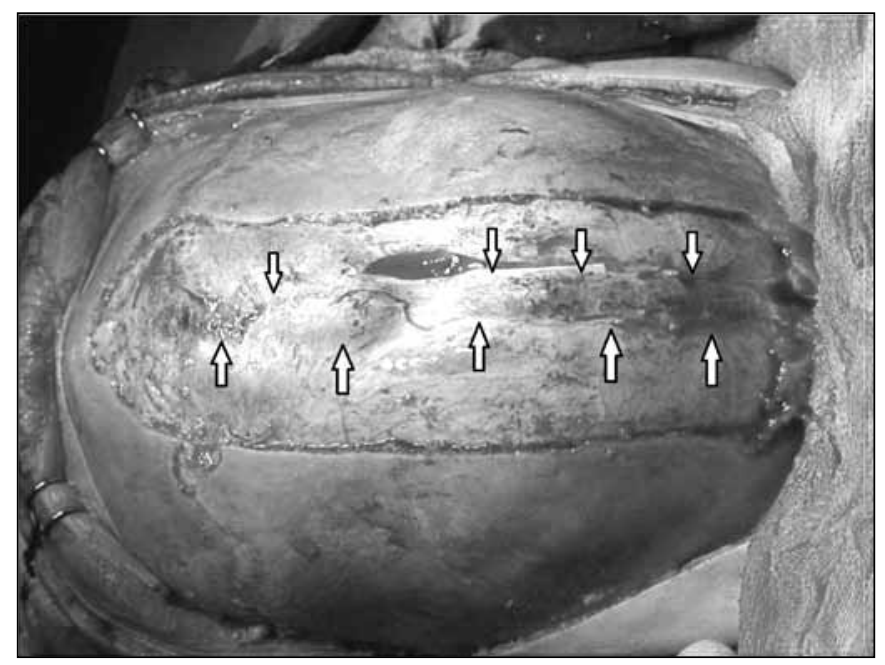

Figure 1: In infants, the dura overlying the (large) superior sagittal sinus (arrows) is thin and carries a potential risk of injury and excessive blood loss.

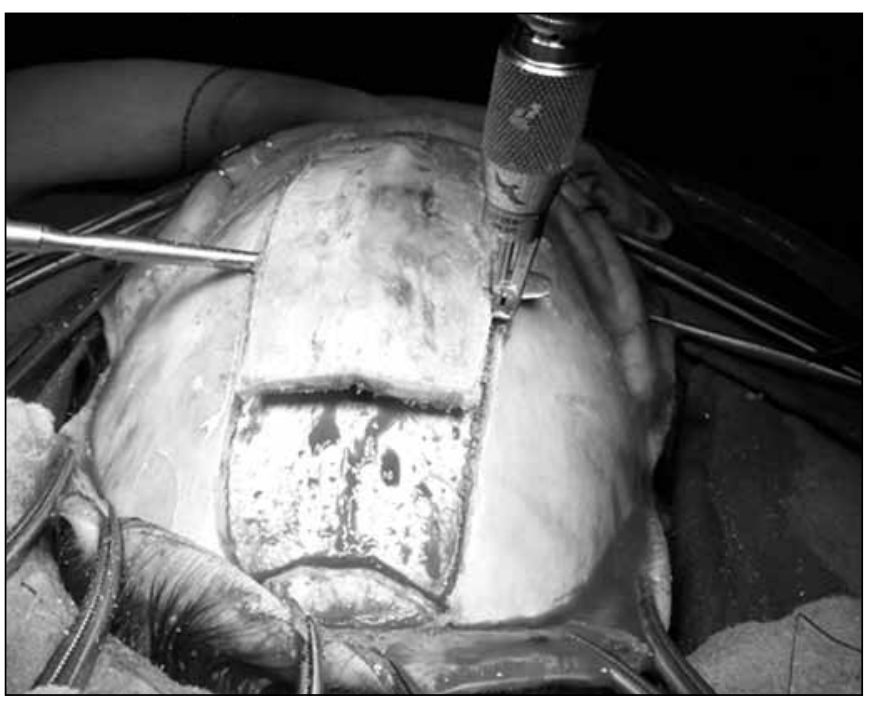

Figure 3: Removal of the midline one-third of the bone safely freed from the underlying dura and superior sagittal sinus.

\section{DISCUSSION}

Many different techniques, from total calvarial re-modelling to minimally invasive strip craniectomies, are used in the surgery for sagittal synostosis $(3,5,6,7,9)$. The common feature of most described surgeries is the removal of the prematurely fused sagittal suture (2). This traditional midline craniotomy consists of the following: dissecting the periosteum over the suture at the anterior fontanel, bilateral parasagittal bone cuts using a craniotome, and elevation of the midline separating the dura from the undersurface of the bone over the superior sagittal sinus from the anterior to the posterior fontanel with coagulation of the emissary veins under the elevated strip bone $(1,8)$. In infants, the superior sagittal sinus lies underneath the entire midline synostotic parietal bone to be removed. Because of the thin and fragile dural sinus leaf, the

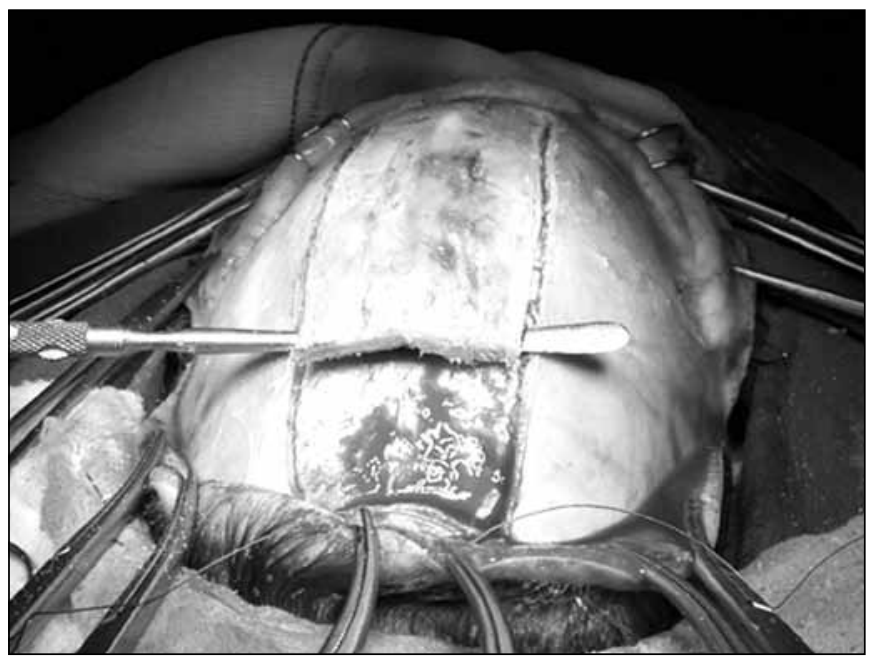

Figure 2: Removal of the anterior one-third of the midline parietal bone in an infant with the head in prone position.

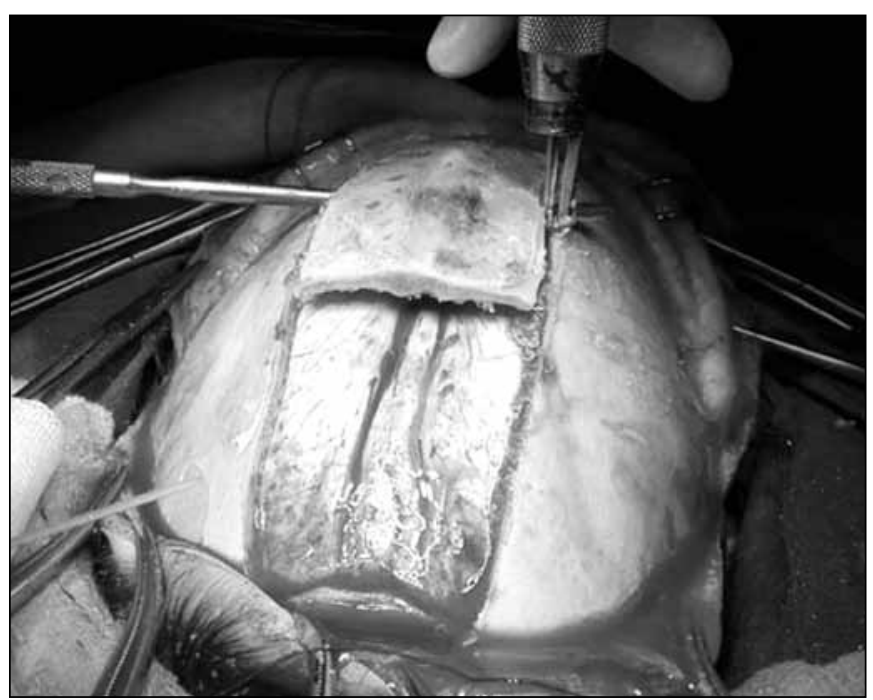

Figure 4: Removal of the posterior one-third of the bone freed from the sinus using an elevator. 
removal carries the potential risk of injury to the sinus and the injury to the superior sagittal sinus with excessive blood loss in an infant is a serious concern. Minor injury to the superior sagittal sinus is reported by Massimi et al. (7). To avoid such a complication, operative techniques like $\pi$-procedures with a strip bone left over from the superior sagittal sinus are described $(4,10)$.

We herein describe a safe technique to remove the sagittal bone between the anterior and the posterior fontanels, trying to minimize the potential risk of dural tear of the superior sagittal sinus and, thus, life-threatening excessive blood loss in infants undergoing conventional surgery for sagittal synostosis. The stepwise removal of the bone with three pieces reduces the potential risk of injury to the thin-walled dural sinus in infants.

\section{CONCLUSION}

The stepwise removal of the midline bone with three smaller pieces is a safe procedure, minimizing the risk of injury to the underlying dural sinus and reducing the risk of sinus bleeding in infants.

\section{REFERENCES}

1. Albright AL: Surgical management of scaphocephaly. Cranial reconstruction techniques. Techniques in Neurosurgery 3: 184-198, 1997

2. Christophis $P$, Jünger $\mathrm{TH}$, Howaldt HP: Surgical correction of scaphocephaly: Experiences with a new procedure and follow-up investigations. J Craniomaxillofac Surg 29: 33-38, 2001
3. Di Rocco F, Knoll BI, Arnaud E, Blanot S, Meyer P, Cuttarree $H$, Sainte-Rose C, Marchac D: Scaphocephaly correction with retrocoronal and prelambdoid craniotomies (Renier's H technique). Childs Nerv Syst 28:1327-1332, 2012

4. Jane JA, Lin KYK: Surgical management of scaphocephaly, $\pi$-squeeze technique. Techniques in Neurosurgery 3:179-183, 1997

5. Jimenez DF, Barone CM: Endoscopic technique for sagittal synostosis. Childs Nerv Syst 28:1333-1339, 2012

6. Massimi L, Tamburrini G, Caldarelli M, Di Rocco C: Effectiveness of a limited invasive scalp approach in the correction of sagittal craniosynostosis. Childs Nerv Syst 23: 1389-1401, 2007

7. Massimi L, Di Rocco C: Mini-invasive surgical technique for sagittal craniosynostosis. Childs Nerv Syst 28:1341-1345, 2012

8. McComb G: Sagittal synostosis repair. Pediatric Neurosurgery. Philadelphia: WB Saunders Company, 2001:363-368

9. Morota N, Ogiwara $\mathrm{H}$, Kaneko $\mathrm{T}$ : Hybrid surgery for scaphocephaly with distraction osteogenesis using skull expanders: Technical note. Childs Nerv Syst 28:1353-1358, 2012

10. Park TS, Robinson S: Nonsyndromic craniosynostosis. In: McLone D (ed). Pediatric Neurosurgery. Philadelphia: WB Saunders Company, 2001:345-366

11. Steinbok P, Heran N, Hicdonmez T, Cochrane DD, Price A: Minimizing blood transfusions in the surgical correction of coronal and metopic craniosynostosis. Childs Nerv Syst 20: 445-452, 2001 